\title{
A pulsatile flow model for in vitro quantitative evaluation of prosthetic valve regurgitation
}

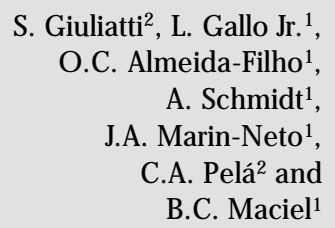

\author{
'Divisão de Cardiologia, Departamento de Clínica M édica, \\ Faculdade de Medicina de Ribeirão Preto and \\ 2Departamento de Física, Faculdade de Filosofia, \\ Ciências e Letras de Ribeirão Preto, U niversidade de São Paulo, \\ Ribeirão Preto, SP, Brasil
}

\section{Correspondence \\ B.C. Maciel \\ Departamento de Clínica Médica FMRP, USP \\ Av. Bandeirantes, 3900 \\ 14048-900 Ribeirão Preto, SP Brasil \\ Fax: + 55-16-633-0869 \\ E-mail: bcmaciel@ fmrp.usp.br}

Research partially supported by FAPESP (No. 89/0528-4) and CN Pq (No. 830025/92-8).

Received August 2, 1999 Accepted January 10, 2000

\section{Abstract}

A pulsatile pressure-flow model was developed for in vitro quantitative color Doppler flow mapping studies of valvular regurgitation. The flow through the system was generated by a piston which was driven by stepper motors controlled by a computer. The piston was connected to acrylic chambers designed to simulate "ventricular" and "atrial" heart chambers. Inside the "ventricular" chamber, a prosthetic heart valve was placed at the inflow connection with the "atrial" chamber while another prosthetic valve was positioned at the outflow connection with flexible tubes, elastic balloons and a reservoir arranged to mimic the peripheral circulation. The flow model was filled with a $0.25 \%$ corn starch/water suspension to improve Doppler imaging. A continuous flow pump transferred the liquid from the peripheral reservoir to another one connected to the "atrial" chamber. The dimensions of the flow model were designed to permit adequate imaging by Doppler echocardiography. Acoustic windows allowed placement of transducers distal and perpendicular to the valves, so that the ultrasound beam could be positioned parallel to the valvular flow. Strain-gauge and electromagnetic transducers were used for measurements of pressure and flow in different segments of the system. The flow model was also designed to fit different sizes and types of prosthetic valves. This pulsatile flow model was able to generate pressure and flow in the physiological human range, with independent adjustment of pulse duration and rate as well as of stroke volume. This model mimics flow profiles observed in patients with regurgitant prosthetic valves.

Spectral and especially color Doppler flow mapping techniques have been used extensively in the clinical setting to estimate noninvasively the severity of valvular regurgitation (1-5). A number of different Doppler methods for quantitation of valve regurgitation have been described, including measurement of the spatial distribution of regur- gitant jets in the receiving chamber $(3,6)$, quantitation of regurgitant flow rate using flow convergence proximal to the orifice $(7,8)$, momentum flux analysis (9), and dimensions of vena contracta $(10,11)$.

An improved understanding of the interrelations between flow mapping and hydrodynamics has brought to light important limi-
Key words
- Flow model
- Echocardiography
- Valvular regurgitation
$\ldots \ldots \ldots \ldots \ldots \ldots \ldots \ldots \ldots$ 
tations of these methods for grading the severity of regurgitation. Technical factors related either to the instrumentation or to the physics of ultrasound and a variety of physiological factors in addition to the volume of regurgitation and the entrainment of the surrounding fluid in the receiving chamber can influence the quantitation of valvular insufficiency by the color Doppler techniques $(10,12-15)$.

The evaluation of the relative influence of these multiple and interrelated factors for quantitative evaluation of valvular regurgitation cannot be adequately performed in the clinical setting. Therefore, in vitro models of valve regurgitation, by producing strict and simultaneous control of multiple variables, play an important role for the methodological validation of Doppler methods for estimating the severity of valvular insufficiency. Several types of in vitro flow models have been designed for Doppler echocardiographic studies (12,16-19). Pulsatile flow models can provide better simulation of the physiological conditions observed in the human cardiovascular system.

We describe here an in vitro pulsatile pressure-flow model designed to simulate pressure and flow patterns documented in the human heart and to provide adequate conditions for quantitative evaluation of valvular regurgitation by color Doppler flow mapping in prosthetic valves strategically placed at the inflow and outflow portions of the flow model. In addition, the system was designed to permit controlled variations of peripheral circulation resistance and chamber compliance.

The flow simulator, depicted in Figure 1, was composed of 1) a computerized pulse generation system controlling a piston driven by stepper motors; 2) acrylic chambers designed to simulate heart chambers, and 3 ) flexible tubes, elastic balloons and reservoirs arranged to mimic the peripheral circulation.

The flow model was filled with a $0.25 \%$ corn starch/water suspension to improve Doppler imaging. The pulsatile flow through the system was produced by a piston driven by two stepper motors (Miniangle stepper, 34PM - CO41 model; Minebea Co.) controlled by an IBM compatible personal computer. Software was developed using Quick Basic 40 to gener-
Figure 1 - Schematic diagram of the flow simulator.

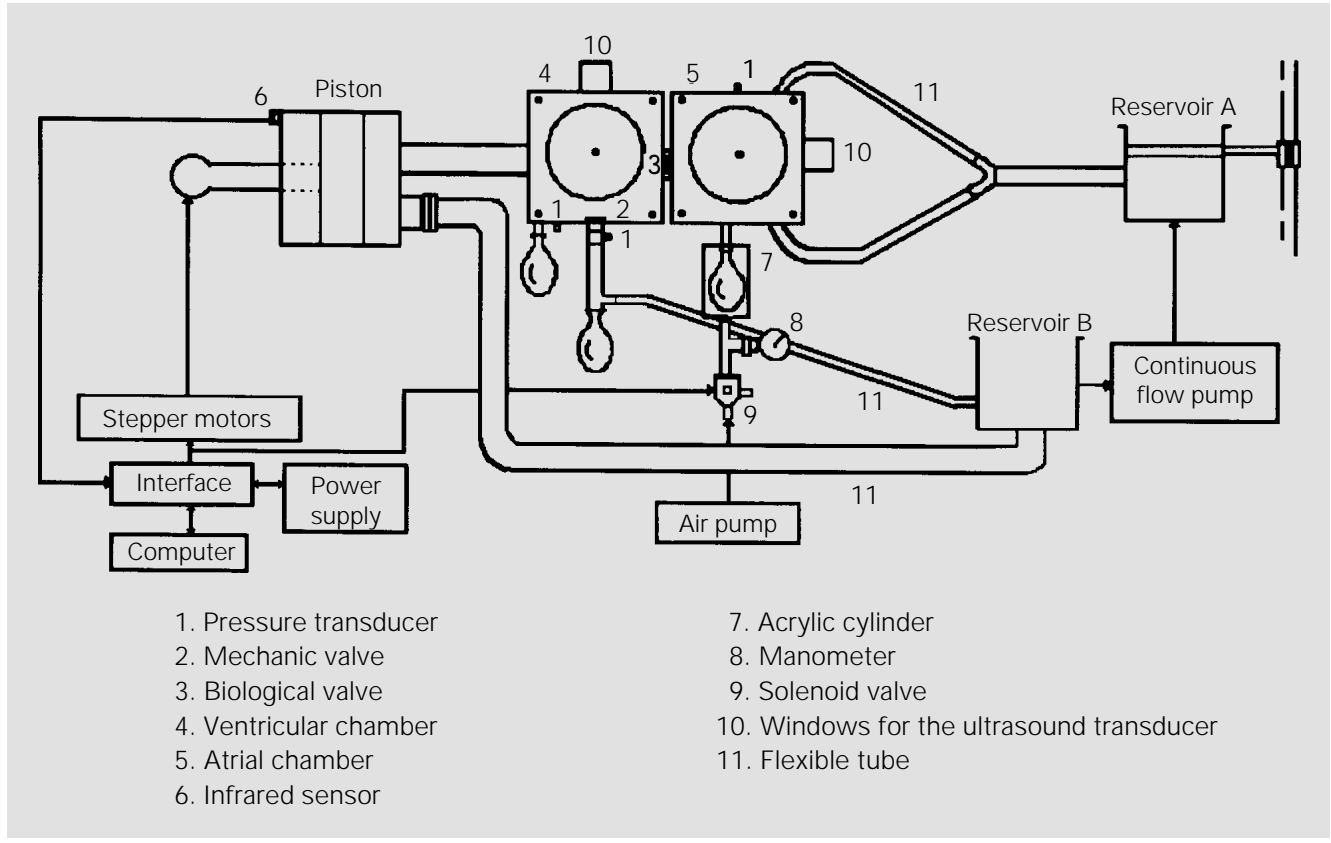


ate a pulsatile function with variable and adjustable profile, amplitude and rate. This software was also used to control the opening of a solenoid valve which was the part of the system designed to mimic atrial contraction. An electronic interface between the computer and the stepper motors was used to meet compatible voltage and current requirements.

The piston was built inside an acrylic chamber which had two connections: at one end it was connected by a non-valved tube to the acrylic chambers designed to simulate "ventricular" and "atrial" heart chambers; at the other end, a valved tube connected the piston to a flexible tube and a reservoir (reservoir B). During forward movement of the piston this valve did not permit flow directed to the reservoir, but during the piston backward movement the chamber was filled with liquid from reservoir $\mathrm{B}$. This mechanism reduced the resistance during the excursion of the piston. Inside the "ventricular" chamber, a replaceable prosthetic heart valve (biological or mechanical) of variable size could be placed at the inflow connection with the "atrial" chamber while another prosthetic valve was positioned at the outflow connection with the flexible tubes, elastic balloons and a reservoir arranged to mimic the peripheral circulation. The balloons were arranged according to the Windkessel model to simulate variable arterial compliances. Fluid level at the atrial reservoir was maintained constant by a continuous flow pump(VEB MLW Prüfgeräte-Werk, UH4 model) which transferred liquid from the peripheral reservoir $\mathrm{B}$ to another one connected to the "atrial" chamber (reservoir A). The height of reservoir A could be changed to obtain different "atrial" pressures.

The compliance of the acrylic "atrial" chamber was modified by connecting it to an elastic balloon filled with the same corn starch/water suspension. To simulate "atrial" contraction, this balloon was positioned inside another acrylic cylinder filled with atmospheric air. This cylinder completely surrounded the balloon. A solenoid valve was connected to the cylinder and to an air pump. An infrared sensor located in the piston was used to synchronize the opening of the solenoid valve during a controlled period of time with the piston movement, allowing atmospheric air to enter the cylinder and to compress the balloon, increasing "atrial" pressure and simulating "atrial" contraction.

The dimensions of the flow model were designed to permit adequate imaging by Doppler echocardiography. Acoustic windows allowed placement of transducers distal and perpendicular to the valves, so that the ultrasound beam could be positioned parallel to the valvular flow. A commercially available ultrasound system (HewlettPackard Sonos 1000, Waltham, MA, USA) with $3.5-$ or $5.0-\mathrm{MHz}$ phased-array transducers was used for imaging flow through the prosthetic valves. Strain-gauge (Statham, $\mathrm{P} 23 \mathrm{Ab}$ ) and electromagnetic transducers (Electromagnetic Blood Flowmeter, SP2200 model) were used for measurements of pressure and flow in different segments of the system. An 8-channel physiologic recorder (Hewlett-Packard 4588A) was used to record these variables. The flow model was also designed to fit different sizes and types of prosthetic valves.

Pressure curves similar to those observed in human ventricular and atrial chambers as well as in the peripheral arterial system were observed in the flow model as shown in Figure 2. Even a dicrotic notch similar to that seen in the aortic pressure curve was obtained with this model. A negative "early diastolic ventricular" pressure varying from -10 to $-30 \mathrm{mmHg}$, probably related to the backward movement of the piston and to the system (tube plus gauge) impedance, was frequently documented. During the "diastolic" period, the backward movement of the piston also influenced the shape of the pulsatile "atrial" pressure curve. However, the mean "atrial" pressure was similar to that observed under physiological conditions.

By changing the amplitude of the piston 

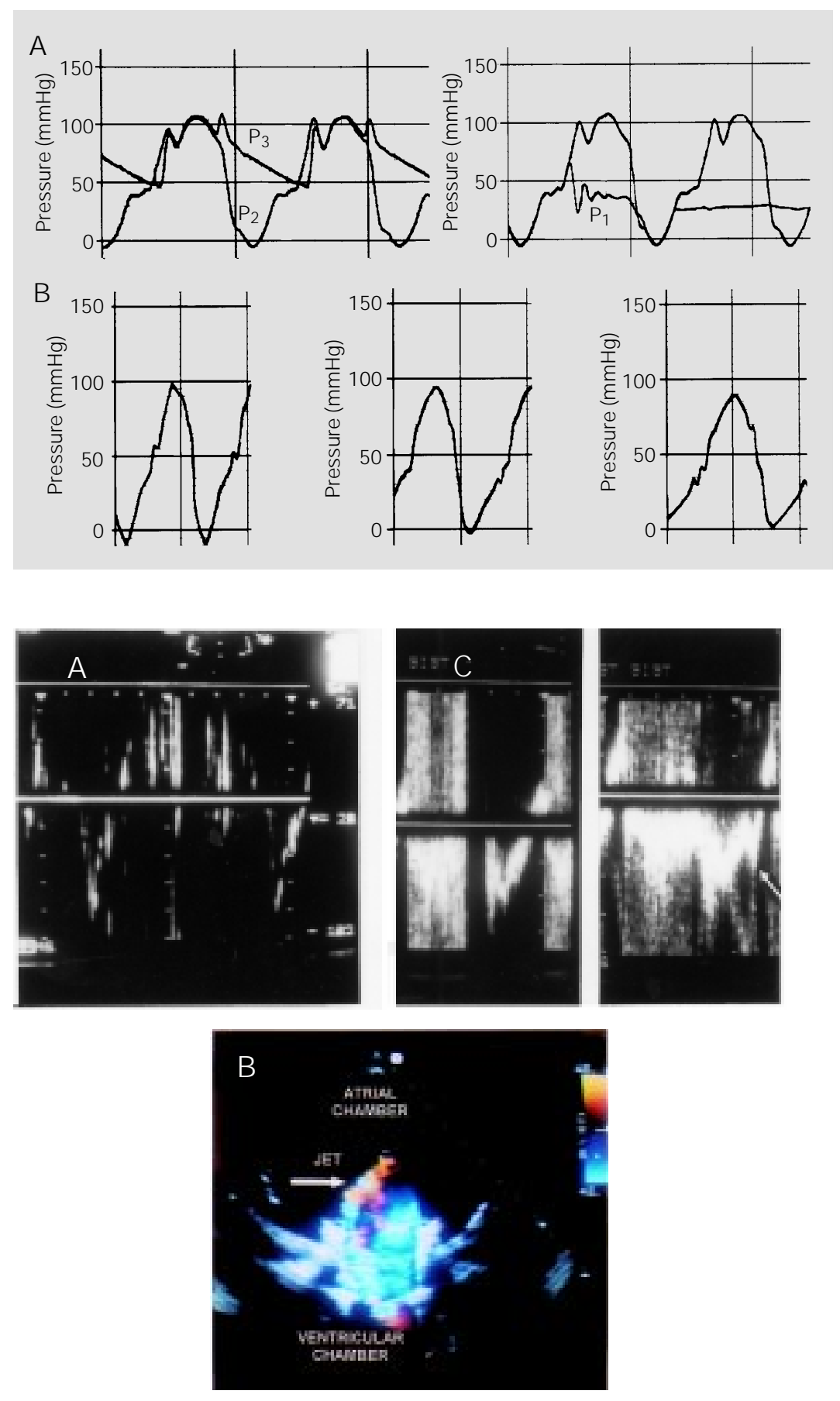

Figure 3 - Panel A, Pulsed Doppler velocities recorded at the outflow of the "ventricular" chamber showing a flow profile similar to that observed in the human left ventricular outflow tract. Panel B, Regurgitant jet as documented by color Doppler flow mapping in a biological prosthetic valve positioned at the "ventricular" inflow level. Panel C, Pulsed Doppler velocities recorded at the inflow of the "ventricular" chamber showing aliasing related to the regurgitant jet (produced in a biological prosthetic valve) and the inflow velocities without (left) and with (right) simulation of "atrial" contraction (arrow represents velocities related to "atrial contraction").
Figure 2 - Panel A, Pressure curves were recorded in the "atrial" $\left(P_{1}\right)$ and "ventricular" $\left(P_{2}\right)$ chambers and also at the "peripheral circulation" $\left(\mathrm{P}_{3}\right)$ level of the flow model. Panel B, Pressure curves were recorded at the "ventricular" chamber level when the rate of pressure increase during forward movement of the piston was modified independently.

movement it was possible to modify pressure and flow generated by the pulsatile flow model within a physiological range (90 to $120 \mathrm{ml} /$ beat). Increasing impedance by localized constriction in the peripheral circulation progressively increased pulse pressure. The flow model allowed variation of pulse rate from 35 to 54 "beats"/min and also independent control of the rate of pressure rise during forward movement of the piston, keeping constant pulse rate and amplitude (Figure 2).

Flow velocities through mechanical and biological prosthetic valves were documented by color Doppler flow mapping and pulsed Doppler. The patterns of normal and regurgitant flows (Figure 3) obtained with this model were similar to those obtained in patients with prosthetic valves (Figure 3). Quantification of the magnitude of valvular regurgitation can be obtained by evaluating flow through prosthetic valves and peripheral circulation with electromagnetic flow meters. When the "atrial contraction" was synchronized with piston movement the velocity profile obtained mimicked the diastolic flow documented at the ventricular inflow (Figure 3).

The in vitro pulsatile flow system described in this investigation was suitable for simulating pressure and flow conditions similar to those observed in the human circulation under physiological conditions. In addition, it allowed a strictly controlled and independent variation of a number of different variables which can influence the magnitude of valvular regurgitation as evaluated by color Doppler flow mapping. Therefore, reproducible right and left human ventricular flow and pressure conditions could be simulated 
with independent adjustments of pulse duration and rate, rate of pressure generation, stroke volume, system impedance and chamber compliances. The flow system was also designed and effectively used to evaluate normal and dysfunctional (regurgitant or stenotic) prostheses of variable types and sizes. The flow model was also able to mimic atrial contraction synchronized with piston movement, thereby producing a "ventricular" chamber filling pattern similar to the human physiological pattern. A cycle-tocycle monitoring of pressure and flow curves in different segments of the flow model assured continuous quantitation of pressure gradients and flow conditions. Considering that this flow model was specifically designed for Doppler echocardiography studies, acoustic windows were strategically positioned to provide adequate visualization of the flow through the prosthetic valves.

Although this flow simulator has been designed for quantitative evaluation of the magnitude of valvular regurgitation by Doppler echocardiographic techniques, it can also be used for a number of different types of investigations including 1) evaluation of the flow pattern through normal valve pros- theses of variable sizes, 2) analysis of the effects of "atrial" or "ventricular" compliance and of "atrial" contraction on "ventricular" filling, and 3) quantitative evaluation of prosthetic valve regurgitation at the "ventricular" outflow and inflow levels.

Some limitations were identified in this pulsatile flow model. Stepper motor power was not able to maintain an adequate excursion of the piston when peripheral resistance was progressively increased. Therefore, this simulator appears to be inadequate for quantitative studies of stenotic prosthetic valves positioned at the "ventricular" outflow level. In addition, only a limited range of pulse rate, varying from 35 to 54 pulses/min, could be generated using this flow model. It would be possible to correct these limitations using more powerful motors and reducing the dimensions of the piston.

In conclusion, the pulsatile flow model described in this investigation was adequate to simulate pressure and flow conditions in the human physiological range and may thus represent an important tool for quantitative evaluation of the magnitude of valvular regurgitation by color Doppler flow mapping.

\section{References}

1. Quinones MA, Young J B, Waggoner AD, Ostojic MC, Ribeiro LG \& Miller RR (1980). Assessment of pulsed Doppler echocardiography in detection and quantification of aortic and mitral regurgitation. British Heart J ournal, 44: 612-620.

2. Miyatake $\mathrm{K}$, Izumi $\mathrm{S}$, Okamoto $\mathrm{M}$, Kinoshita N, Asonuma H, Nakagawa $\mathrm{H}$, Yamamoto K, Takamiya M, Sakakibara H $\&$ Nimura Y (1986). Semiquantitative grading of severity of mitral regurgitation by real-time two dimensional Doppler flow imaging technique. J ournal of the American College of Cardiology, 7: 82-88.

3. Helmcke F, Nanda NC, Hsiun MC, Soto B, Adey CK, Goyal RG \& Gatewood RP (1987). Color Doppler assessment of mitral regurgitation with orthogonal planes. Circulation, 75: 175-183.

4. Sahn DJ \& Maciel BC (1988). Physiologi- cal valvular regurgitation-Doppler echocardiography and the potential for iatrogenic heart disease. Circulation, 78: 1075-1077.

5. Maciel BC, Simpson IA, Valdes-Cruz LM, Recusani F, Hoit B, Dalton N, Weintraub R \& Sahn DJ (1991). Color flow Doppler mapping studies of physiologic pulmonary and tricuspid regurgitation: evidence for true regurgitation as opposed to a valve closing volume. J ournal of the American Society of Echocardiography, 4: 589-597.

6. Spain MG, Smith MD, Grayburn PA, Harlamert EA \& DeMaria AN (1989). Quantitative assessment of mitral regurgitation by Doppler color flow imaging: angiographic and hemodynamic correlations. J ournal of the American College of Cardiology, 13: 585-590.

7. Recusani F, Bargiggia GS, Yoganathan AP, Raisaro A, Valdes-Cruz LM, Sung HW,
Bertucci C, Gallati M, Moisés VA, Simpson IA, Tronconi L \& Sahn DJ (1991). A new method for quantification of regurgitant flow rate using color Doppler flow imaging of the flow convergence region proximal to a discrete orifice. An in vitro study. Circulation, 83: 594-604.

8. Bargiggia GS, Tronconi L, Sahn DJ , Recusani F, Raisaro A, De Servi S, ValdesCruz LM \& Montemartini C (1991). A new method for quantification of mitral regurgitation based on color flow Doppler imaging of flow convergence proximal to regurgitant orifice. Circulation, 84: 14811489.

9. Thomas JD, Liu CM, Flachskampf FA, O'Shea J P, Davidoff R \& Weyman AE (1990). Quantification of jet flow by momentum analysis. An in vitro color Doppler flow study. Circulation, 81: 247-259. 
10. Switzer DF, Yoganathan AP, Nanda NC, Woo Y-R \& Ridgway AJ (1987). Calibration of color Doppler flow mapping during extreme conditions in vitro: a foundation for a reliable quantitative grading system for aortic incompetence. Circulation, 75: 837-846.

11. Feshke W, Omran H, Manz M, Köhler J, Hagendorff A \& Lüderitz B (1994). Colorcoded Doppler imaging of the vena contracta as a basis for quantification of pure mitral regurgitation. American J ournal of Cardiology, 73: 268-274.

12. Maciel BC, Moises VA, Shandas $R$, Simpson IA, Beltran M, Valdes-Cruz LM \& Sahn DJ (1991). Effects of pressure and volume of the receiving chamber on the spatial distribution of regurgitant jets as imaged by color Doppler flow mapping: an in vitro study. Circulation, 83: 605-613.

13. Simpson IA, Valdes-Cruz LM, Sahn DJ , Nurillo A, Tamura T \& Chung K-J (1989).
Doppler color flow mapping of simulated in vitro regurgitant jets: evaluation of the effects of orifice size and hemodynamic variables. J ournal of the American College of Cardiology, 13: 1195-1207.

14. Hoit BD, J ones $M$, Eidbo EE, Elias $W \&$ Sahn DJ (1989). Sources of variability for Doppler color flow mapping of regurgitant jets in an animal model of mitral regurgitation. J ournal of the American College of Cardiology, 13: 1631-1636.

15. Utsunomiya T, Ogawa T, King SW, Sunada E, Moore GW, Henry WL \& Gardin J M (1990). Effect of machine parameters on variance display in Doppler color flow mapping. American Heart J ournal, 120: 1395-1402.

16. Yearwood TL \& Chandran KB (1980). Experimental investigation of steady flow through a model of the human aortic arch. J ournal of Biomechanics, 13: 1075-1088.

17. Hasenkam JM, Westphal D, Reul H,
Gormsen J, Giersiepen M, StodkildeJ orgensen H \& Paulsen PK (1987). Threedimensional visualisation of axial velocity downstream of six different mechanical aortic valve prostheses measured with a hot-film anemometer in a steady state flow model. J ournal of Biomechanics, 20: 353-364.

18. Ojha M, J ohnston KW, Cobbold RSC \& Hummel RL (1989). Potential limitations of center-line pulsed Doppler recordings: an in vitro flow visualisation study. J ournal of Vascular Surgery, 9: 520-525.

19. Simpson IA, Fisher J, Reece IJ , Houston AB, Hutton I \& Wheatley DJ (1986). Comparison of Doppler ultrasound velocity measurements with pressure differences across bioprosthetic valves in a pulsatile flow model. Cardiovascular Research, 20: 317-321. 